\title{
UNINTENDED DURAL INJURY IN DEGENERATIVE LUMBAR SPINAL SURGERY: A RETROSPECTIVE STUDY
}

\author{
(1) Soner Çivi \\ Başkent University Faculty of Medicine, Department of Neurosurgery, Adana, Turkey
}

\begin{abstract}
Objective: Unintended dural injury rate in all spinal surgeries is between $0.2 \%$ and $20 \%$. This rate approaches the upper rates in degenerative lumbar surgery. Unintended dural injury occurs due to many factors and revision surgery is one of these reasons. As a result of the injury, the possibility of neurological deficits is not high, but conditions such as headache, pesudomeningocele, superficial infection, meningitis and radicular pain can occur. However, these complications can be solved today. In our study, we aimed to evaluate unintended dural injury and its results retrospectively.

Materials and Methods: Between 2011 and 2018, 376 (225 female and 151 male) patients who had undergone decompression and posterior lumbar pedicle screw fixation were included in the study. Fifty-eight patients were operated due to revision surgery. The mean patient age was 57.35 years (range: $33-79$ years). Dural injuries were sutured with microsurgical technique and sealant was used. All patients were recommended bed rest between 24 and 48 hours.

Results: The number of unintended dural injuries was 26. Eleven patients with dural injury were operated for revision surgery. There was pseudomeningocele in three patients, superficial wound infection in three patients, meningitis in one patient, and transient radicular symptoms in 12 patients. Twenty-one patients had early cerebral hypotension and all responded to the medication.

Conclusion: Unintended dural injury occurring in surgeries performed due to lumbar degenerative process does not significantly affect surgical results. It is very important to properly diagnose and treat additional complications caused by unintended dural injury.

Keywords: Unintended dural injury, complications, degenerative spine surgery
\end{abstract}

\section{INTRODUCTION}

Unintended dural injury is a common complication during degenerative lumbar spinal surgery. Dural injury rate in all spinal surgeries is between $0.2 \%$ and $20 \%{ }^{(1-4)}$. Unintended dural injury increases with increasing age, female sex, surgical experience, invasive surgery, revision surgery and degenerative process. In degenerative process, this rate approaches the upper limits. The average rate is $17 \%(4,5-9)$. Cerebrospinal fluid (CSF) leakage caused by dural injury may complicate the postoperative period with headaches, nausea, vomiting, back pain, abducens nerve palsy, fistula formation, pseudomeningocele, surgical site infections, meningitis, and in rare circumstances, chronic subdural hematomas ${ }^{(10-15)}$. However, these complications can be handled by developing surgical techniques. In this study, we aimed to retrospectively evaluate the causes and consequences of unintended dural injury.

\section{MATERIALS AND METHODS}

\section{Patients}

All patients who underwent spine surgery for degenerative conditions performed at our institution between 2011 and 2018 were included in the study. We excluded patients treated for tumors, infections, and deformity from this study. This retrospective study included 376 adult patients (225 female and 151 male) who had undergone decompression and posterior lumbar pedicle screw fixation.

\section{Study Approval}

The need for informed consent was waived owing to the retrospective nature of the study.

\section{Surgical Technique}

All patients in the study underwent decompression and pedicular screw fixation due to the degenerative process. Dural 
injuries were sutured with microsurgical technique and sealant (Tisseel-Baxter Healthcare Corporation) was used. Postoperative management with bed rest was questioned in relation to the size of the dural tear. All patients were recommended 24-48 hours of bed rest.

\section{RESULTS}

The demographic characteristics of the patients enrolled in the study are shown in Table 1 . Three hundred seventy-six patients were included in the study. Two hundred twenty-five (59.84) patients were female and 151 (40.16\%) patients were male. The mean patient age was 57.35 years (range: $33-79$ years). Fifty-eight (15.4\%) patients underwent revision surgery. Twenty-six (6.91\%) patients had unintended dural injury. Fifteen (3.98\%) of the dural injuries were detected in patients who underwent primary surgery and $11(2.96 \%)$ were seen in patients who underwent revision surgery. The ratio of dural injury in revision cases was $25.86 \%$ and the ratio of dural injury in primary cases was $3.45 \%$. Three had pseudomeningocele and three had superficial wound infection. Only one patient was treated for meningitis. Radicular pain and paresthesia occurred in 12 patients who were given medical treatment. Twenty-one patients had early cerebral hypotension and all responded to medical treatment (Table 2).

\section{DISCUSSION}

Diagnostic and therapeutic methods developed in recent years have increased the surgical rates due to lumbar degenerative

Table 1. Patient demographics and findings

\begin{tabular}{lll}
\hline None of patients & 376 & \\
\hline Male-rate & 151 & $40.16 \%$ \\
\hline Female-rate & 225 & $59.84 \%$ \\
\hline Mean age, range & 57.35 & $33-79$ \\
\hline Primary surgery-rate & $318 / 376$ & $84.6 \%$ \\
\hline Revision surgery-rate & $58 / 376$ & $15.4 \%$ \\
\hline Dural tear in patient group & $26 / 376$ & $6.91 \%$ \\
\hline $\begin{array}{l}\text { Ratio of dural damage in revision } \\
\text { cases }\end{array}$ & $15 / 58$ & $25.86 \%$ \\
\hline $\begin{array}{l}\text { Ratio of dural damage in primary } \\
\text { cases }\end{array}$ & $11 / 318$ & $3.45 \%$ \\
\hline
\end{tabular}

Table 2. Complications

\begin{tabular}{lll}
\hline Pseudomeningocele & 3 & $11.53 \%$ \\
\hline Superficial wound infection & 3 & $11.53 \%$ \\
\hline Radicular pain and paresthesia & 12 & $46.15 \%$ \\
\hline Early cerebral hypotension & 21 & $80.76 \%$ \\
\hline Meningitis & 1 & $3.84 \%$ \\
\hline
\end{tabular}

process. Unintended dural injury is a common complication during degenerative lumbar spine surgery (Figure 1-2). Dural injury rate is between $0.2 \%$ and $20 \%$ in all spinal surgeries ${ }^{(1-4,10)}$. In open surgery series for lumbar degenerative process, unintended dural injury rate was $8.11 \%$ (range: $2-20 \%$ ). In our series, unintended dural injury was $6.91 \%$ in the whole group whereas in primary cases, this rate decreased to $3.45 \%$ and the rates were consistent with the literature. Surgical invasiveness and manipulation of dura has been reported as a general predictor of dural injury and appears to be associated with overall dural injury rates.

Dural injury incidence in a group of patients who underwent revision surgery was $25 \%$ and was not associated with the years of experience of the surgeon ${ }^{(16)}$. In our study, the ratio of dural injury in revision cases was found to be $25.86 \%(15 / 58)$. Dural injury is one of the most common complications in spinal surgery. Although different methods have been described for the treatment of this complex problem, the primary treatment

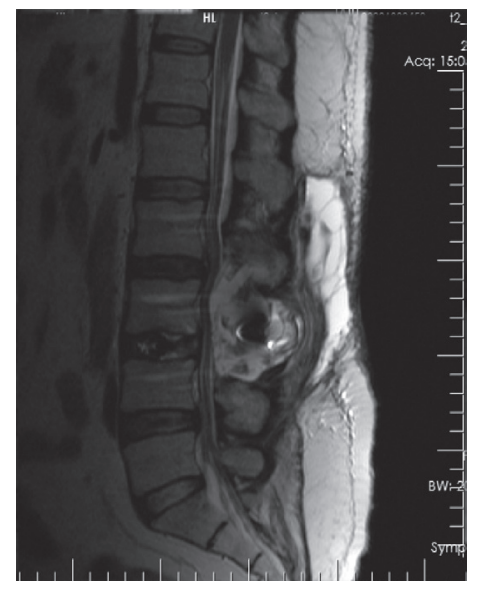

Figure 1. Dural leakage is observed in the T2 - weighted MRI Sagittal Image

MRI: Magnetic resonance imaging

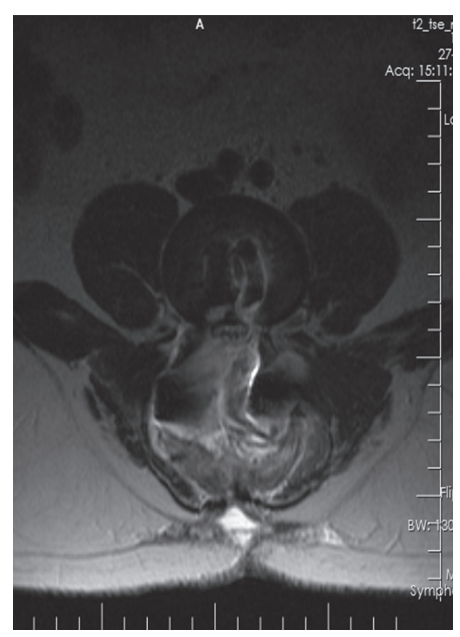

Figure 2. Dural leakage is observed in the T2 - weighted MRI Axial Image MRI: Magnetic resonance imaging 
of dural injuries is primary repair. Closed subarachnoid drainage; laser tissue welding; grafts consisting of muscle, fat, or fascia; blood patches; fibrin-adhesive or cyanoacrylate polymer sealant; application of Gelfoam to the tear; bed rest; and avoidance of the use of wound drains are other treatment methods ${ }^{(17)}$. Due to the small number of patients in the literature, it is difficult to compare the effectiveness of treatment modalities; however, most authors advocated using a combination of these methods ${ }^{(17)}$. In our study, we applied the combination of microsurgery repair, sealant use and bed rest. Bed rest time is controversial due to comorbidities that may develop.

Rest for a long time can lead to problems such as deep vein thrombosis, pneumonia, and additional $\cos ^{(18)}$. For this reason, we did not apply bed rest longer than 48 hours for our patients. Intracranial hypotension $(\mathrm{IH})$ is a clinical syndrome in which absolute or relative hypovolemia of CSF results in various neurological symptoms ${ }^{(19)}$. An increasing number of publications in recent years shows that $\mathrm{IH}$ is no longer a rare syndrome. $\mathrm{IH}$ can occur spontaneously or iatrogenically. This group of patients is treated by anesthesiologists and neurologists as the first reason in iatrogenic cases is lumbar puncture. However, IH knowledge is essential for spine surgeons, spinal surgery and complications of degenerative spinal disorders may be secondary causes of $\mathrm{IH}^{(19)}$. In our study, we encountered headache due to early $\mathrm{IH}$ in 21 of 26 patients with dural injury. In patients responding to symptomatic treatment, no further complications related to $\mathrm{IH}$ occurred. However, it should be kept in mind that post-surgical CSF leakage may cause temporary symptoms such as headache, as well as more serious intracranial complications.

latrogenic pseudomeningocele is an extradural cystic formation caused by CSF leak after spinal surgery ${ }^{(18)}$. The incidence of unintended durotomy is anywhere from 0.3 to $13 \%$ and most frequently occurs as a result of lumbar laminectomy ${ }^{(20)}$.

The lumbar region pseudomeningocele is more common because more lumbar surgery is performed today and the CSF pressure is higher in this area. In the study of Swanson and Fincher involving 1700 patients, the incidence of postoperative pseudomeningocele was shown to be $0.07 \%{ }^{(20)}$. Hawk and Kim ${ }^{(20)}$ reported pseudomeningocele rate as $0.8 \%$ in his retrospective study in 1408 patients.

In our study, the rate of patients who developed dural injury was $11.53 \%$ while this rate was $0.79 \%$ in the whole series. Our findings were consistent with the literature.

Postoperative meningitis after spinal surgery is rare but can lead to serious complications, including death. Twyman et al. ${ }^{(21)}$ showed its incidence as $0.18 \%$ in its 2180 cases. Lin et al. ${ }^{(22)}$ reported an incidence of postoperative meningitis as $0.10 \%$ (21 of 20,178 surgeries). Morris et al. ${ }^{(23)}$ reported bacterial meningitis in two cases of dural tears with posterior instrumentation with pedicle screws. It achieved good results with timely diagnosis and treatment in both patients. This study showed that postoperative meningitis was a rare complication after spinal lumbar surgery. Be aware of fever, neck stiffness, and consciousness disturbance findings that develop after spinal surgery. Intraoperative unintended dural injury is the most important predictor. Early diagnosis and appropriate antibiotic treatment for at least two weeks can lead to a good outcome. In our study, the symptoms of meningitis were encountered in one patient and there was a dural injury in the patient. Good results were obtained with early diagnosis and appropriate treatment. The causes of superficial wound infection following dural damage were defined as CSF fistula, prolonged operation time, and need for long bed rest ${ }^{(24)}$. In our study, we encountered superficial wound infection in three patients. This complication occurred in patients with obesity and Diabetes Mellitus. It was not associated with dural injury.

Takenaka et al. ${ }^{(24)}$ said that dural injury was associated with an increased risk of postoperative neurological deficits, and dural injury formation was an important risk factor for postoperative neurological deficits. McMahon et al. ${ }^{(25)}$ and Williams et al.(26) showed that dural injury was associated with postoperative neurological deficits in two different large series. However, we cannot conclude a causal relationship between dural injury and neurological deficits.

However, entering the dura intraoperatively may injure neural elements, or additional procedures performed by surgeons to repair the dural injury may lead to neurological deficit ${ }^{(24)}$. In our study, temporary paresthesia and radiculopathy were detected in $12(46.15 \%)$ of 26 patients with dural injury, but no serious neurological deficits were observed. These complaints were attributed to additional manipulations performed during repair.

\section{Conclusion}

Unintended dural injury occurring in surgeries performed due to lumbar degenerative process does not significantly affect surgical results. Dural injury is common during revisions. Additional temporary complications may occur. However, good or excellent results can be obtained when appropriate treatment methods are applied.

\section{Ethics}

Ethics Committee Approval: Retrospective study.

Informed Consent: Retrospective study.

Financial Disclosure: The authors declared that this study received no financial support.

\section{REFERENCES}

1. Papavero L, Engler N, Kothe R. Incidental durotomy in spine surgery: first aid in ten steps. Eur Spine J. 2015;24:2077-84.

2. Ghobrial GM, Theofanis T, Darden BV, Arnold P, Fehlings MG, Harrop IS. Unintended durotomy in lumbar degenerative spinal surgery: a 10-year systematic review of the literature. Neurosurg Focus. 2015;39:E8.

3. Stromqvist F, Jonsson B, Stromqvist B. Dural lesions in lumbar disc herniation surgery: incidence, risk factors, and outcome. Eur Spine J. 2010;19:439-42.

4. Khan MH, Rihn J, Steele G, Davis R, Donaldson WF 3rd, Kang JD, et al Postoperative management protocol for incidental dural tears during 
degenerative lumbar spine surgery: a review of 3,183 consecutive degenerative lumbar cases. Spine (Phila Pa 1976). 2006;31:2609-13.

5. Stolke D, Sollman W, Seifert V. Intra- and postoperative complications in lumbar disc surgery. Spine (Phila Pa 1976). 1989;14:56-9.

6. O'Connor D, Maskery N, Griffiths WE. Pseudomeningocele nerve root entrapment after lumbar discectomy. Spine (Phila Pa 1976). 1998;23:1501-2.

7. Koo J, Adamson R, Wagner Jr FC, Hrdy DB. A new cause of chronic meningitis: infected lumbar pseudomeningocele. Am J Med. 1989;86:103-4.

8. Eismont FJ, Wiesel SW, Rothman RH. Treatment of dural tears associated with spinal surgery. J Bone Joint Surg Am. 1981;63:1132-6.

9. Radcliff KE, Sidhu GD, Kepler CK, Gruskay J, Anderson DG, Hilibrand A, et al. Complications of Flat Bed Rest After Incidental Durotomy. Clin Spine Surg. 2016;29:281-4.

10. Cammisa FP Jr, Girardi FP, Sangani PK, Parvataneni HK, Cadag S, Sandhu HS. Incidental durotomy in spine surgery. Spine (Phila Pa 1976). 2000;25:2663-7.

11. Hodges SD, Humphreys SC, Eck JC, Covington LA. Management of incidental durotomy without mandatory bed rest. A retrospective review of 20 cases. Spine (Phila Pa 1976). 1999;24:2062-4.

12. Kalevski SK, Peev NA, Haritonov DG. Incidental Dural Tears in lumbar decompressive surgery: Incidence, causes, treatment, results. Asian J Neurosurg. 2010;5:54-59.

13. Bosacco SJ, Gardner MJ, Guille JT. Evaluation and treatment of dural tears in lumbar spine surgery: a review. Clin Orthop Relat Res. 2001;389:238-47.

14. Guerin P, El Fegoun AB, Obeid I, Gille O, Lelong L, Luc S, et al. Incidental durotomy during spine surgery: incidence, management and complications. A retrospective review. Injury. 2012;43:397-401.

15. Saxler G, Kramer J, Barden B, Kurt A, Pförtner J, Bernsmann K. The long-term clinical sequelae of incidental durotomy in lumbar disc surgery. Spine (Phila Pa 1976). 2005;30:2298-302.
16. Smorgick Y, Baker KC, Herkowitz H, Montgomery D, Badve SA, Bachison $C$, et al. Predisposing factors for dural tear in patients undergoing lumbar spine surgery. J Neurosurg Spine. 2015;22:483-6.

17. Wang JC, Bohlman HH, Riew KD. Dural tears secondary to operations on the lumbar spine. Management and results after a two-yearminimum follow-up of eighty-eight patients. J Bone Joint Surg Am. 1998;80:1728-32.

18. Oitment C, Aref M, Almenawar S, Reddy K. Spinal Dural Repair: A Canadian Questionnaire. Global Spine J. 2018;8:359-64.

19. Inamasu J, Guiot BH. Intracranial hypotension with spinal pathology. Spine J. 2006;6:591-9.

20. Hawk MW, Kim KD. Review of spinal pseudomeningoceles and cerebrospinal fluid fistulas. Neurosurg Focus. 2000;9:e5.

21. Twyman RS, Robertson P, Thomas MG. Meningitis complicating spinal surgery. Spine (Phila Pa 1976). 1996;21:763-5.

22. Lin TY, Chen WJ, Hsieh MK, Lu ML, Tsai TT, Lai PL, et al. Postoperative meningitis after spinal surgery: a review of 21 cases from 20,178 patients. BMC Infect Dis. 2014;23;14:220.

23. Morris BJ, Fletcher N, Davis RA, Mencio GA. Bacterial meningitis aftertraumatic thoracic fracture-dislocation: two case reports and review of the literature. J Orthop Trauma. 2010;24:e49-53.

24. Takenaka S, Makino T, Sakai Y, Kashii M, Iwasaki M, Yoshikawa $H$, et al. Dural tear is associated with an increased rate of other perioperative complications in primary lumbar spine surgery for degenerative diseases. Medicine (Baltimore). 2019;98:e13970.

25. McMahon $P$, Dididze M, Levi AD. Incidental durotomy after spinal surgery: a prospective study in an academic institution. J Neurosurg Spine 2012;17(1):30-6.

26. Williams BJ1, Sansur CA, Smith JS, Berven SH, Broadstone PA, Choma TJ, et al. Incidence of unintended durotomy in spine surgery based on 108,478 cases. Neurosurgery. 2011;68:117-23. 